\title{
Se-ducere: esse obscuro objeto de desejo
}

Anna Maria balogh USP/UNIP 


\section{Resumo}

No artigo se analisa a última obra-prima de Buñuel, Cet Obscur Objet du Désir, com ênfase nas questões relativas à sedução, ao erotismo e ao desejo. Tal aproximação se faz com base nas reflexốes de reputados autores que abordaram o tema tais como Octavio Paz, Francesco Alberoni, Jean Baudrillard e Marilena Chauí, entre outros. Tratam-se também dos elementos de linguagem considerados mais singulares na representação do erotismo por parte de Buñuel nofilme. Os principais elementos linguageiros do cineasta seriam as experimentações no tocante à montagem e na utilização das atrizes, ás tưpturás nơ șistema de expectativàs tradicionàl no tocante aos papéis do homem e da mulher no erotismo e na sedução. Além dos mencionados, merecem menção $o$ uso de alternâncias entre a narração e o comentário, entre o relato e a moldura, bem como um paradoxal recurso a uma simbologia de cunho erótico bem tradicional dentro de um filme considerado de ruptura e de vanguarda.

\section{Palavras-chave}

Cinema, Erotismo, Sedução, Montagem

\section{Abstract}

This article is an approach to the theme of eroticism - desire and seduction - in Luis Buñuel's last master-piece, Cet Obscur Objet $d u$ Désir. The analysis is mainly based on reflexions of Octavio Paz, Francesco Alberoni, Jean Baudrillard and Marilena Chauí, authors of well-known works on the subject. There's also an emphasis in some singular strategies used by the filmmaker to represent his original view on seduction: Strategies such as the experimental usage of editing and acting, the subversive view of both female and male reactions related to desire and seduction, the use of narration and comment to tell a story, the recourse to surprisingly traditional erotic symbols in the context of an avant-garde film.

\section{Key words}

Cinema, Eroticism, Seduction, Editing 


\section{Cet Obscur Objet du Desir}

Trata-se de um filme da trilogia final de Luis Buñuel, em conjunto com $O$ discreto Charme da Burguesia e $O$ fantasma da Liberdade, precisamente o último deles. A obra foi considerada um dos dez melhores filmes da década de 70 pela Revista Time e relata a história de um homem rico e elegante de meia-idade (Fernando Rey), consumido pelo ardente desejo que sente em relação a uma jovem bem mais moça e muito sensual.

Parece significativo que o último filme do cineasta trate da temática do desejo. Fruto de uma época de grandes restrições políticas, religiosas e morais em seu país, o genial cineasta nunca deixou de demarcar, por vezes de forma selvagem, o desejo de autonomia e liberdade nas temáticas que o instigaram. Eis aquí, poiš, num filme, $o$ testamento de um grande rebelde no tocante ao erotismo. Não deixa de ser uma ironia do diretor o fato de ter escolhido uma obra literária para adaptar tendo como protagonista um cavalheiro sessentão consumido pelo desejo. Sabemos por sua auto-biografia que o próprio realizador diz ter deixado de sentir desejo precisamente nessa idade e achou que o fato representava um alívio na sua vida. Supondo que o cineasta tenha efetivamente dito a verdade em seu relato biográfico, tem-se aí bem o tipo de escolha de um grande artista que se dizia 'católico e ateu, graças à Deus' ...

Por uma destas brincadeiras do destino, a atriz primeiramente cogitada para o papel principal; não pode interpretá-lo e, numa conversa com seu produtor, Sérgè Silberman, o cineasta resolveu dar.o papel da provocante Conchita a duas atrizes: Carole Bouquet e Angela Molina, conforme se relata em Meu Último Suspiro, relato auto- 
biográfico do realizador escrito com Jean-Claude Carrière, roteirista, colaborador assíduo das obras do cineasta espanhol, inclusive esta.

$\mathrm{Na}$ verdade, o filme traz algumas das questões perenes do erótico: a paixão de um homem bem mais velho, por uma mulher bem mais jovem e muito atraente, a questão da posse do corpo desejado, a correspondencia ou a assimetria nos desejos de duas pessoas no momento em que se relacionam, a sedução. Como não poderia deixar de ser, Buñuel subverte o padrão usual dos filmes do gênero em que o homem velho e desejante no geral faz uso e, por vezes, até abuso de seu poder para buscar na mulher desejada a juventude e a energia perdidas ou escassas. Isso ocorre em Camille Claudel, na relaçấo de Rodin com sua discípula Camille, tão corrosiva, que termina por levá-la à perda do juízo e ao enclausuramento, a pedido de seus próprios familiares. Ocorre nas diferentes versõès fílmicas de $O$ Corcunda de Notre Dame, em que um bispo tão provecto quanto devasso persegue a jovem e sensual cigana, sempre protegida pelo corcunda. Em Lady Hawke é o velho e repugnante Bispo de Áquila que faz um encantamento para separar a belá Isabeau do capitão Navarre a quem ela ama è que a ama também, mas a quem o bispo dévasso deseja. Ou seja, no geral há um vitimizar da mulher, frágil, bela e indefesa por parte do homem detentor do poder e que a cobiça. Assim, frente a ela, ele se apresenta como um grande predador, não è désejado pela vítíma, pela qual ele mesmo sente, no entanto, um intenso desejo.

\section{Cinema e montagem, sedução e jogo}

Buñuel não é cineasta para se limitar ao aparente, nunca se contentaria em permanecer na mera superfície das coisas. Ao escolher o lado mais autêntico, por vezes mais selvagem do erotismo, o realizador espanhol está buscando aquilo que se esconde sob a obviedade. Sob a pele das palavras há cifras e códigos, como diz Carlos Drummond, . cabe ao cineasta desvendá-los de algum modo, também sob a pele das imagens, nos movimentọ da câmera e do corpo, nos diálogos mordazes do filme. Mas é sobretudo no uso magistral da montagem, que a obra traz um diferencial extraordinário. 
Da idéia nascida a partir da discussão com o produtor: a utilização de duas atrizes num único papel, é que surge essa proeza única. Ao jogar com as alternâncias entre as duas atrizes, Buñuel se respalda no seu profundo conhecimento das características do cinema, também revelado em Meu Último Suspiro nas palavras que seguem:

Creio que o cinema exerce um certo poder hipnótico sobre os espectadores. Basta observar as pessoas que saem de uma sala de cinema, sempre em silencio, a cabeça baixa e o ar distante. (...) A hipnose cinematográfica, livre e inconsciente, deve-se, sem dúvida, à obscuridade da sala, mas também às mudanças de planos, de luzes $e$ aos movimentos da câmera, que enfraquecem a inteligência crítica do espectador e exercem sobre ele uma espécie de fascinação e violação. (1982: 95-96)

A maioria dos autores que se dedicaram ao estudo do erotismo, do amor e da sedução, tais como Octavio Paz, Francesco Alberoni, Jean Baudrillard, entre outros, são unânimes em afirmar que o erotismo é da ordem do signo e da cultura e, portanto, no erotismo as forças da natureza são canalizadas de modo a não romper o edifício da estrutura social. Trata-se de um equilíbrio no geral bem instável e até mesmo frágil. No caso da representação do erotismo através do cinema, tudo se torna mais complexo, posto que, como deixa claro a afirmação de Buñuel, se está tratando de um processo de sedução através de outro processo de sedução, aquele utilizado pela linguagem fílmica e suas características singulares. O cinema traz, com freqüencia, essa visão metonímica do corpo, também própria do erótico no ver, sempre sutil, do Prêmio Nobel, Octavio Paz, em livro dedicado ao tema:

Al abrazar a la presencia, dejamos de verla y ella misma deja de ser presencia. Dispersión del cuerpo deseado: vemos sólo unos ojos que nos miran, una garganta iluminada por la luz de una lámpara y pronto vuelta a la noche, el brillo de un muslo, la sombra que desciende 
del ombligo al sexo. Cada uno de los fragmentos vive por si sólo pero alude a la totalidad del cuerpo. Esse cuerpo que, de pronto, se ha vuelto infinito. (2003, p. 204)

Já em seus primeiros filmes, como L'Age d'Or e Chien Andalou, os mais explicitamente ligados ao surrealismo, Buñuel não hesita em mostrar os aspectos mais instintivos da sexualidade, um casal fazendo sexo em pleno chão, diante de muita gente, inclusive representantes da igreja; em outra cena Lya Lys aparece chupando o dedão do pé de uma estátua de pedra do jardim; como nos lembra o terapeuta Jean Yves Leloup, o pé é um símbolo erótico tanto nos povos primitivos quanto nos civilizados (2000, p. 29-30).

Em $O$ cão andaluz há uma sequiência com alternância de planos em que se enfatiza primeiro as mãos de um homem buscando os seios de uma mulher vestida, depois as mãos acariciando os seios desnudos e, por fim, a derrière da mulher nua, os cortes conduzindo o olho para materializações bem cruas do desejo mais instintivo. Em filmes como Tristana, o cineasta joga' com o fetichismo, a perna mecânicà da protagonista vivida pela bela Catherine Deneuve. Em Belle de Joür, tảmbém com a célebre atriz que vive uma burguesa à prostituição naš horas vagas; o realizador brinca com a sugestão; conta com o lado escuro de nossa mente: qual seria o conteúdo daquela bendita caixinha que se vê numa das cenas do prostíbulo? Além das astúcias da própria:linguagem fílmica, Buñuel sabe perfeitamente que o ato de sugerir pode deslanchar um processo muito mais perverso em termos eróticos-no público do que o de mostrar.

O primeiro dos elementos inquietantes do filme é a referida duplicação da protagonista. Apesar de as duas atrizes que representam Conchita não terem grande semelhança física, há gente que na época de estréia do filme, antes que se espalhasse a notícia do estratagema utilizado, nem notava a troca de atrizes. Seduções de uma montagem primorosa. Ao contrário de outros filmes sobre o tema da sedução, nesse são bem mais raros os planos próximos, por motivos óbvios. As atrizes representam, na verdade, dois pólos do próprio feminino ou ainda, do psiquismo humano em si: um lado de calor, de 
desejo e outro lado de frieza; de rechaço. As trajetórias humanas se alternam entre ambos os polos. No filme, modulações passionais e inquietudes : se traduzem também em mobilidades espaciais entre a França e da Espanha, países dos quais as duas atrizes são representações físicas emblemáticas. $\odot$ lado mais caliente está representado por Angela Molina, uma típica espanhola de origem andaluza. $\mathrm{O}$ lado mais frio, está representado pela francesa Carole Bouquet do tipo bon-chic-bon-genre, e, portanto, mais distante, mais remplie de soi-même. As duas apenas acenam para essa diferença fundamental, mas não nos enganemos, ambas são igualmente capazes de fazer Mathieu-Mateo, o velho cavalheiro apaixonado, de trouxa, de fantoche, sentidos de pantin, na obra literária, La femme et le Pantin, de onde se origina o filme. Nesse sentido, o filme toca um dos elementos mais delicados da relação a dois, seja ela erótica, seja ela amorosa: a confiança, a relação fiduciária que não pode ser quebrada sem consequiências maiores para a relação.

O nome da protagonista feminina não é em absoluto casual. Não devemos esquecer que o símbolo da concha costuma estar inextrincavelmente ligado ao órgão sexual feminino na cultura popular, como aponta discretamente o dicionário de símbolos sexuais de Jean Boullet a partir do conhecido quadro renacentista de Bøticelli:

Coquille. La naissance de Vénus, immortalisée par Boticelli, est l'image même: du symbolisme sexuel idéalisé. Le peintre a sublimé un calembour graphique connu depuis l'antiquité, une involontaire plaisenterie mythologique fondée sur l'aspect féminin de certains coquillages. (1961, p. 71-73)

A concha é, pois, uma representação simbólica bastante crua e evidente, do obscuro objeto do desejo, objeto esse, cuja complexidade vai muito além da mera representação material ou simbólica. Além disso, há um intrincado tecido de relações que envolve o próprio desejo em si, como se depreende da perspicaz análise do termo feita em ensaio de Marilena Chauí: 
A palavra desejo tem bela origem. Deriva-se do verbo desidero que, por sua vez, deriva-se do substantivo sides (mais: usado :no plural, sidera), significando a figura formada por um conjunto de estrelas, isto é, as constelações.....sidera é usado para indicar a influência dos astros sobre o destino humano, donde sideratus, siderado: atingido ou fulminado por uma astro. De sidera, vem considerare - examinar com cuidado, respeito $e$ ve: neração:-e desiderare - cessar de olhar (os astros), deixar de ver (os: astros).(...)... considerare é consultar o alto para nele encontrar o sentido e o guia seguro de nossas vidas. Desiderare, ao contrário, é estar despojado dessa referência, abandonar o alto ou ser por ele abandonado. (1990, p. 22)

Mathieu, ao entregar-se ao desejo, deixou de ligar-se aos astros, de tê-los como referência,' está abandonado, perdido em sua obssesão; ele está verdadeiramente siderado por Conchita; ou seja, fulminado pelos astros. Ele é um homem de muitas posses, vai desenvoltamente de uma propriedade a outra, na Espanha ou na França; viaja em primeira classe; veste se com refinamento, num tempo em que os homens andavam de chapéu, de luvas, de terno e um eventual bastão. Ou seja, tem tudo o que pode aspirar na vida... exceto esse obscuro objeto do desejo.

\section{Conchita: a imagem da sedução}

Convém relembrar como tudo começou. Mathieu conhece a jovem Conchita como criada no casarão do seu primo que é promotor è ónde ele vai jantar. Imediatamente se encanta com a moça, achà suas mãos muito finas, mãos de qúem nunca trabalhou, segundo ele. Nessa cena temos a Conchita francesa. Dá um jeito de atraíla para seus aposentos, sob pretexto de querer tomar um vinho antes de dormir, mas a Conchita espanhola, a que aparece na cena, é mais do que sabida para escapar-lhe no momento exato. 
Como dissemos, o cineasta é consciente de que representa um processo de sedução com a arte mais sedutora e enganosa de todas, a sétima arte. $\mathrm{O}$ filme inteiro é um jogo de esconde-esconde ao qual já aludia René Bazin ao falar do cinema e apontar as constantes entradas e saídas de personagens na tela. Há uma íntima relação entre esses jogos de esconde-esconde do cinema dos quais o cineasta faz o máximo proveito na montagem e o próprio processo de sedução da maneira como o define Jean Baudrillard, um dos estudiosos do tema. Dentro deste campo semântico do amor e do erotismo, é a sedução a que melhor representa esse jogo, com suas astúcias e refinamentos, como se observa em filmes como Ligações Perigosas, mas também em Esse Obscuro Objeto do Desejo, nos quais se atualizam os jogos apontados pelo teórico francês:

Omisiones, denegaciones, recogimientos, rodeos, decepciones - todo eso se encamina a provocar este estado segundo, secreto de una verdadera seducción. (Baudrillard, 1987, p. 103)

Conchita, em suas duas versões, sabe melhor do que ninguém levar Mathieu ao limiar da loucura em termos de desejo. $\mathrm{O}$ que Conchita faz é atrair o velho cavalheiro desejante com profusas juras de amor apaixonadas e uma imagem de boa moça, constantemente reiteradas. Ao mesmo tempo, no entanto, sempre que Mathieu está a ponto de conseguir consumar as relações sexuais com a moça, Conchita se faz de ofendida por qualquer bobagem, vai embora sem aviso, ou interpõe obstáculos de todo o tipo à consumação do ato sexual em si, numa perfeita ilustração das idas e vindas próprias da sedução às quais Baudrillard se refere...

Há uma similaridade bastante grande com alguns dos aspectos de Ligações Perigosas, apesar da distância das obras na diacronia. Conchita, como grande sedutora que é, se assemelha a Valmont em certos aspectos, a começar por ser, tal como o visconde, uma mestra na arte das palavras. Suas frases dizem exatamente o que o velho apaixonado quer ouvir: que ela o ama com exclusividade, que ela é virgem (yo soy mozita), que não trabalha para não sofrer 
más influências, nem estar em más companhías, e assim por diante. Mas, da mesma forma como na trajetória de Valmont, há um fosso gigantesco entre as suas ações e as suas palavras. A mãe de Conchita é uma espécie de duplo hiperbólico dela, uma beata que não faz nada além de ir à igreja e para a qual nada importa. Ela sabe muito bem se fazer de desentendida no tocante ao tipo de relação de Mateo com sua filha. Cochita revela um cinismo similar, nada lhe importa, nem as maiores regalias, o único que lhe interessa é dançar.

De mozita nada, Conchita esconde um apaixonado jovem, parte do seu grupo de flamengo, na própria casa do velho a quem acaba de recusar acesso às suas delícias mais recônditas, sendo que o mesmo não acontece com Morenito, o amante a quem esconde. Nas pressas de abrigá-lo no quarto, um vaso do corredor cai e quebra. A simbologia é 6bvia, como esclarece Boullet em sua obra: cruche cassée: cas de symbolisme sexuel dissimulé. Il s'agit...de l'impression de la défloration (1961, pg.85). Desvirginar, privilégio que, de certo, não foi de Mateo, apesar de se dizer donzela, ela já é mulher. Resta ao velho cavalheiro ficar batendo na porta do quarto trancada, em desespero. Ela não só não ama a Mathieu, como o faz de tonto com um amante muito mais jovem. Arranca todo o dinheiro que pode do velho apaixonado que o distribui a ela e à mãe com grande prodigalidade, ao mesmo tempo em que faz de conta que 0 dinheiro não lhe importa. Ou seja, é uma consumada manipuladora.

O filme leva ao paroxismo o mecanismo de alternâncias entre estados de ânimo como a combustão do desejo e a inércia polar da frieza, entre a atração e a repulsão em termos eróticos, que correspondem à proximidade e à distância em termos proxêmicos, ao calor e ao frio em termos de sensações, à exaltação e ao desprêzo em termos de modulações passionais, em resumo, a obra é, por assim dizer, um verdadeiro tobogã do desejo.

Em determinadas seqüências contrastam também a ordem e o caos ou ao menos a desordem, ou ainda o refinamento em contraposição à grossura, ou ao puro instinto. Assim, podemos considerar que a obra oscila entre momentos de proximidade à civilização ou outros tendentes à barbárie. O passional tem inúmeras modulações entre os extremos. Uma das jogadas que Conchita faz, é dei- 
xar o seu quarto numa das residências de Mathieu toda desarrumada, depois de um desentendimento entre ambos, aliás se trata de um espaço isomórfico do que ela faz da vida do velho admirador: o desejo que nele provoca desordena, subverte tudo, o mundo dele fica de pernas para $o$ ar. Cada vez que ela desaparece com o dinheiro que ele lhe deu, ele sai correndo atrás perguntando dela buscando-a, deixando sua vida harmônica de cavalheiro rico e aisé de lado por conta dos desmandos de Conchita. Ele segue os destinos dela e abandona, assim, o comando de seu próprio destino.

Cabe lembrar ainda que o filme retrata uma época em que a mulher parece ser mais desejada pelo homem, menos disponível, e há menos opções para o exercício da sexualidade. Assim sendo, as paixões são também, mais fortes, por vezes mais primitivas e intensas, ou até mesmo obssesivas: possuir uma mulher ainda é considerado um trunfo. Um signo de virilidade e de poder.

Francesco Alberoni, ao falar do erotismo, estabelece algumas diferenças fundamentais entre o masculino e o feminino, uma delas é a questão das duas temporalidades básicas dos dois gêneros. Para o autor, há uma íntima relação entre perfeita o femino e

o desejo de continuidade, de proximidade, de intimidade, a necessidade de sentir-se continuamente procurada, amada, desejada. $O$ prazer de estar abraçados, de respirar 0 mesmo ar. E o masculino: o descontínuo, que necessita de intervalos de tempo, de variedade. (1988, p. 125)

O analista italiano observa ainda que a trajetoria erótica do homem tem na descontinuidade temporal a sua característica principal. Trata-se de uma defesa, é a sua maneira de não se deixar prender pela mulher. Em Cet Obscur Objet du Désir, há uma inversão, uma evidente troca de papéis quanto às características fundantes do masculino e do feminino apontadas. Conchita é aquela que quer a independência e a descontinuidade no relacionamento erótico, papéis no geral reservados aos homens.

Buñuel, sempre subvertedor, e um tanto selvagem em suas rupturas, representa precisamente a personagem feminina, como o 
oposto do que sé esperáa dela. Buñuel nos apresenta uma Conchita fria, calculista, fugidia e manipuladora e, claro, muito pouco desejosa de éstar sempre com seu admirador. O homem, que Alberoni considerà como aquele que geralmente escapa dos laços do amor, teria sua representação mais emblemática - no limite da descontinuidade erótica - no mito de D. Juan. No filme, aquele que déseja estar continuamente com Cochita, privar de seu amor e de sua companhía é Mateo, como ela o chamá $\mathrm{Na}$ verdade, se trata de uma relação totalmente assimétrica, não só em tèrmos da grande diferença de idade, mas também pelófato de que Conchita não ama, só usa Mateo, que é verdadeiramente äpaixonado, mas sem ser correspondido. A ésse respeito, Octavio Paz, em suas argutas observações nos esclarece:

La infidelidad puede ser consentida o no, frecuente $u$ ocasional, si es practicada por sólo una de las partes, ocasiona a la outra graves y penosas humillaciones: su amor no tienne reciprocidad. El infiel es insensible, cruel y en ambos casos no puede amar realmente. (1993; p. 118)

No que se refere a questão do desejo e, como visto no belo ensaio de Marilena Chaúí, Mateo realmente parece ter sido abandonado pelos astros e definitivamente escravo dos caprichos de Conchita. A trajetória de Mateo está prevista no título da obra literária que originou o filme, além de representar um exacerbamento de uma característica não muito lisonjeira do masculino apontada por Alberoni em seu estudo sobre o erotismo:

A mulher conservá, em todos os instantes de sua relação amorosa, a capacidade de percepção e de avaliação. $O$ homem não; quando está excitado eroticamente, perde ainda o pouco de perspicácia que possui. (1988, pg.189)

E se, de fato, também na opinião do autor, $O$ erotismo masculinó é anseio egoístico de gozo (1988, p. 49), a perversa e sedutora Conchita tudo fará para conservar a Mateo submisso às suas 
vontades, posto que o cavalheiro revela claramente as fraquezas mencionadas.

\section{Impedir e proibir para melhor provocar}

Como já observaram inúmeros estudiosos sobre o tema, neste caso José Paulo Paes em sua introdução às traduções da poesia erótica clássica, o interdito é um dos mais explosivos atiçadores do desejo:

Paradoxalmente... o prazer encontra seu maior estímulo não na liberdade de perseguir até onde quiser os seus objetivos, mas no constante interdito de fazê-lo, 'o interdito criador do desejo' em que Bataille vê 'a própria essência do erotismo"”. (1991, p. 15)

Conchita, como grande sedutora que é, incorpora as características do masculino que lhe servem, rejeita as do feminino que não the servem, ressalvadas as que atraem o macho desejante, e joga impiedosamente com o exacerbamento do desejo de Mathieu provendo, ela mesma, uma série de proibições, impedimentos, obstáculos e retardamentos contínuos à plena realização do desejo masculino: a posse.

Além das fugas estratégicas e constantes, outro de seus estratagemas prediletos é o adiamento. Sim, ela vai deixar que o admirador a possua, mas não naquela noite, na noite seguinte, na qual ela evidentemente já não estará em lugar algum e assim sucessivamente. O adiamento é da ordem do temporal, mas ela usa outros estratagemas da ordem do físico e do espacial. Quando Mateo, como o chama a Conchita espanhola, está em plena combustão e ela finalmente parece disposta a ceder, pede um tempo para se trocar e que ele apague a luz. Quando ele finalmente chega à cama e a acaricia está radiante - e ela o adverte: - ne chante pas la victoire trop tôt! De fato, quando as suas mãos sequiosas percorrem o corpo dela, ele topa com a uma espécie de calça-espartilho, rigorosamente amarrada e inexpugnável para a sua absoluta exasperação. Quando está 
prestes a possuir a mulher de seus ardentes desejos, ela se apresenta com uma versão moderna do cinturão de castidade!!!

Como é óbvio, os obstáculos espacias são mais fortes, mais pregnantes na linguagem. fílmica. Após outro dos inúmeros sumiços de Conchita, Mathieu consegue localizá-la em Sevilha. Em suas investigações, ele descobre que ela está dançando flamengo em um local noturno, vai lá e ela diz que irá recebê-lo no andar de cima, após seu número de dança. Ao chegar ao local apontado, o que o velho cavalheiro vê através de uma porta envidraçada é o obscuro objeto de seu desejo, Conchita, totalmente nua, dançando em privé para uma série de turistas japoneses mesmerizados ante sua beleza e sua dança provocativa. Enfurecido, ele quebra os vidros da porta e, enciumado, expulsa todo o público que assistia à exibição de Conchita.

Cabe lembrar que há uma relação bastante estreita da dança com o erotismo, mais recentemente, considerou-se marcante a cena de tango em $O$ Perfume de Mulher, quando dois corpos encontram seu ritmo harmônico numa dança, este parece um prelúdio do que poderá acontecer quando os mesmos corpos se encontrem ao fazer amor. Significativamente Mateo e Conchita nunca dançam juntos... O caráter independente e provocador de Conchita parece casar perfeitamente com a força assertiva da dança flamenca que lhe dá tanto prazer, com sons pronunciados de sapateado e caștanholas, é ela quem marca o ritmo dessa relação...

Os inúmeros obstáculos físicos que se reiteram ao longo do filme e que se interpõem entre Mathieu e o objeto de seu desejo, irão levá-lo muitas vezes, seja à exasperação, seja ao desespêro. Do ponto de vista passional se representam uma trajetória de decepção, perda de confiança e de impotência por parte do homem e uma trajetória de rejeição, provocação e escárnio por parte da mulher.

O ápice da humilhação do cavalheiro é quando ele compra uma cașa para Conchita em Sevilha com a esperança de ganhá-la definitivamente para si. Mateo lhe dá os papéis da escritura e as chaves da casa e ela promete entregar-se a ele no belo jardim interno no estilo andaluz pontualmente à meia-noite, num nova estratégia de adiamento da qual ele bem que poderia desconfiar, já a estas alturas. De novo, estamos diante de um simbolismo explicitamente 
de ordem sexual: Serrure: le trou de la serrure est un symbole féminin (il se complète du symbolisme phallique type: la clef). (Boullet, 1961, p. 214) À meia-noite em ponto quando Mathieu chega ao portão de ferro que dá acesso ao jardim andaluz, uma nova e grande decepção o espera: ele está hermeticamente fechado. Conchita vem recebê-lo no portão, que permanece fechado e é mordaz e despectiva com o apaixonado. Depois de ter feito juras de amor nas cenas anteriores e dizer que queria casar, depois de ganhar sua casa de presente, ela lhe diz, através das grades de ferro do portão: - Je suis libre de toi pour toute la vie. Mateo, j'ai horreur de toi... Tu me dégoutes! E, finalmente, quando vê o velho cavalheiro paralisado e imóvel diante do portão, chama a Morenito e diz: Tu ne veux pas t'en aller, alors reste et regarde Morenito, mon amant. Il est beau, il est jeune... e termina por ter relações com o seu amante jovem no jardim diante do estupefato Mateo cuja confiança em Conchita foi traída em grande estilo. Mais uma vez, Buñuel nos instiga a imaginar a relação sexual, sem jamais mostrá-la, ela parece estampada apenas no rosto petrificado de Mateo e no espaço off de nossa imaginação.

\section{A moldura da sedução: o relato do cavalheiro}

Toda a história dos diversos estados de ânimo do velho senhor apaixonado, em suas diferentes modulações: desejo, esperança, decepções, felicidades efêmeras, humilhações, é contada no marco de uma viagem de trem, que o cavalheiro faz para Paris, na qual comparte uma cabine de primeira classe com passageiros interessados em sua história. O estratagema permite que o relato funcione como uma moldura para a história da sedução, por um lado, e, por outro lado, serve para tirar um pouco da solidão de Mathieu e resgatar a sua auto-estima mais do que ferida ao compartilhar com outros o seu relato.

A história começa a partir da cena em que os ocupantes da cabina vêem que ele joga a água de um regador em cima de Conchita. Depois da humilhação que ela lhe impôs em Sevilha, ainda por cima quer subir no mesmo trem! Os companheiros de cabine olham es- 
pantados e um anão que é psicólogo lhe diz que gostaria de connaître l'origine de votre geste ato e ele responde: Il vaut mieux arroser quelqu'un que l'assasiner..., a tal ponto chegou a indignação de Mathieu. Para bom observador, a cena nos remete matreiramente aos primórdios do cinema: L'arroseur arrosé, dos irmãos Lumière. A partir daí, ele se sente à vontade para contar as suas desventuras amorosas aos companheiros de viagem, dois homens, uma mulher e sua filha.

Ao compartilhar suas agruras com os companheiros de cabine, Mathieu se consola e se introduz dentro da narrativa a modalidade do comentário, que representa um acréscimo qualitativo ao discurso, conforme já apontado de forma certeira por Gianfranco Bettetini :

...el comentario es, por el contrario, un componente del discurso mucho más tenso, porque el sujeto enunciador está implicado directamente y porque su actitud comunicativa pretende una notable atención participativa por parte del destinatario. La elección de un modelo de articulación entre relato y comentario comporta una referencia a una posición precisa - de un individuo, de un grupo o de un contexto social - respecto a su. traducción en instancias informativas. (1984, p.74)

Ao falar com os demais de seus infortúnios, Mateo se liberta um pouco de seu peso e a narrativa tem finalmente a sua sanção que é de todo enganosa, tanto quanto a montagem. A sociedade mais burguesa e mais fina representada pelos ocupantes da cabina de primeria classe não vê com bons olhos a exploração selvagem que Conchita faz do cavalheiro, a tal ponto que a jovem senhora manda a filha brincar nos corredores do trem quando Mateo se prepara para contar as passagens mais picantes. Todos colocam cuidadosamente as suas máscaras, as 'personas' de gente cosmopolita e chique, mas o cineasta nos diz que elas são inúteis, o instinto e o desejo são mais fortes: as cenas finais mostram Mateo e a Conchita 'espanhola', mais uma vez juntos, passeando numa galeria. Afastam-se de uma 
vitrina cheia de objetos simbólicos, tais como uma toalha branca rasgada que uma mulher remenda e eis que, de repente, ouve-se um estrondo de uma bomba e eles desaparecem em meio à explosão.

Como diz Guimarães Rosa em Grande Sertão: Veredas, viver é muito perigoso... E nem poderia ser de outra forma, pois, como comprovam muitos filmes e obras de arte, inclusive Cet Obscur Objet du Désir, quando Eros não encontra seu caminho livre e verdadeiro é frequente que desemboque no impulso freudiano contrário. $\mathrm{O}$ erotismo a morte andam num ritmo paralelo, o filme alterna as idas e vindas de Mateo atrás de Conchita com frequentes ataques terroristas a bomba, até que ocorre esse estrondo final, na galeria. Como diz Alberoni, retomando Bataille:

Existem na natureza duas forças. Uma que tende ao individualismo e o indivíduo quer sobreviver. Outra que tende à fusão e, dessa maneira, à decomposição do indivíduo, à sua morte. Esta segunda força é a violência. No erotismo as duas operam. $O$ indivíduo quer permanecer ele mesmo e, todavía, fundir-se com o outro. (1988, p. 64)

Razão pela qual, o mesmo Guimarães Rosa nos lembra sabiamente que Coração da gente, o escuro: escuros.

$\mathrm{Na}$ verdade, os sentimentos fundantes do homem se resistem à semântica comum das palavras, bem como à gramática costumeira das imagens, é necessário um tour de force na linguagem verbal, como a poesia, e outro na linguagem cinematográfica, como esse primoroso exercício experimental de montagem rodeado de um denso universo simbólico e diálogos mordazes para que se possa atingir o limiar dos sentidos que se deseja expressar... 


\section{Bibliografia}

ALBERONI, Francesco.1988. O Erotismo. Fantasias e Realidades do Amor e da Sedução. São Paulo, Círculo do Livro,

BAUDRILLARD, Jean.1987, De la Seducción. Madrid, Cátedra.

BETTETINI, Gianfranco. 1984. La Conversación Audiovisual. Madrid, Cátedra.

BOULLET, Jean.1961, Symbolisme Sexuel dans les Traditions Populaires. Paris, Éditions Jean-Jacques Pauvert.

BUÑUEL, Luis .1982, Meu último suspiro. Rio de Janeiro, Nova Fronteira.

CHAUÍ, Marilena.1990, Laços do Desejo, in Gerd Bornheim. O Desejo. São Paulo, Cia. Das Letras, pp.16-86.

LELOUP, Jean-Yves.2000, O Corpo e seus símbolos. Petrópolis, RJ, Editora. Vozes.

PAES, José Paulo. 1990, Poesia Erótica em Tradução. São Paulo, Cia. Das Letras.

PÀZ, Octavio.1993, La Llama Doble. Amor y Erotismo. Barcelona, Editorial Seix Barral.

PEÑUELA CAÑIZAL, Eduardo (Org.). 1993, Um Jato $n a$ Contramão: Buñuel No México. São Paulo, Editora Perspectiva.

\section{Filmografia:}

ESSE OBSCURO OBJETO DO DESEJO. Cet Obscur Objet du Désir. Luis Buñuel França, 1978. Elenco: Fernando Rey, Julien Berteau, Carole:Bouquet e. Angela Molina. Do romance La Femme et le Pantin, de Pierre Louys.Cor, Som, Legendado. VHS. 